\title{
A collaborative approach to the use of archives in information literacy teaching and learning in an arts university
}

\author{
Adele Martin-Bowtell and Rebekab Taylor
}

W hy do significant parts of our art libraries collections remain undiscovered and unused? Seemingly invisible to students and staff, the university archive strong room creates a barrier, preventing our students and researchers from accessing and browsing materials, as they would with our open shelf collections. What happens when archive materials are freed from their confines, brought out into the studio and explored and used by arts students? Better still, what happens when librarian, archivist and academic collaborate to make this happen, enabling increased awareness of these resources and facilitating information literacy skills learning? Conclude this with an artistic response to this method of teaching and learning and you have the Animation Archive Day at the University for the Creative Arts. The day formed part of a longer term initiative put together by the archivist and librarian to raise awareness among students and staff of the opportunities to utilize archives in their subject specific creative arts learning and education. The project recognizes the importance of allowing students to steer and interact creatively with archive use in a library context.

As art librarians, we are aware of our users' demand and requirement for a wide range of resources. In an arts university, students use the object as much as text based resources in their research and practice. Whilst our libraries may take our collections into the realm of artists' books and/or other printed material of rare or high research value, we can often overlook our natural partner in arts education: the archive. For this paper we take the definition of archive from the Society of American Archivists:

Materials created or received by a person, family or organisation, public or private, in the conduct of their affairs and preserved because of the enduring value contained in them or as evidence of the functions and responsibilities of their creator, especially those materials maintained using the principles of provenance, original order and collective control; permanent records. ${ }^{1}$
At the University for the Creative Arts (UCA), through collaboration between librarian, archivist and academics, we are exploring the challenges and ways of bringing archives and objects into creative arts learning and education to embed information literacy into both studio and academic practice, using the full spectrum of our resources.

This article will use, as our case study, the Animation Archive Day project launched in December 2013 where the Bob Godfrey animation collection was brought into the studio for use by Computer Animation Arts (CAA) students at the university. Employing existing teaching practices for information literacy and using strong links with academics, already established by librarians, a collection of archive materials were made available to students. Informed by emerging practice in other institutions students were encouraged to interact creatively with the resources and to produce 


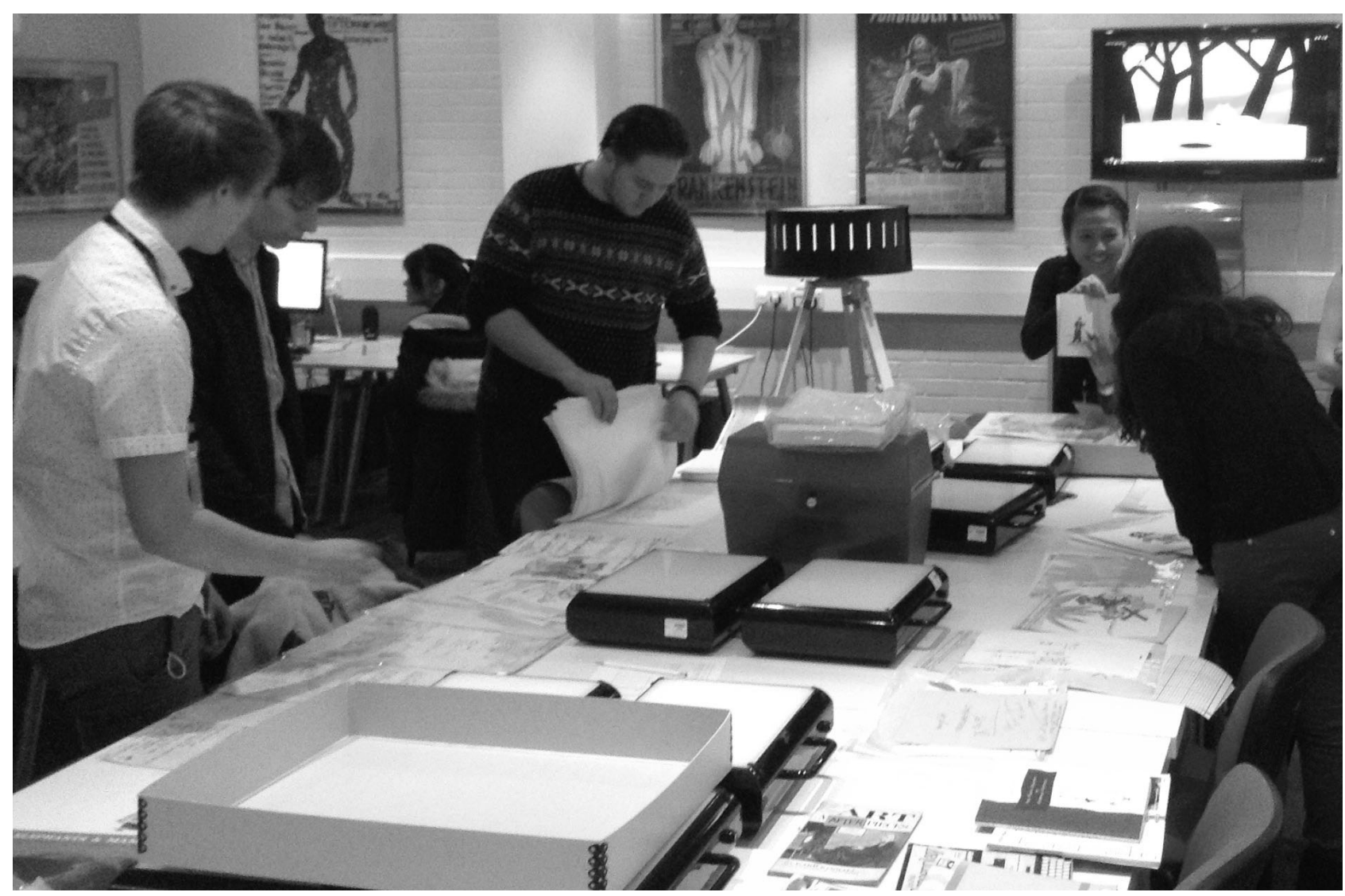

Fig. 1. First year Computer Animation Arts students enjoying Animation Archives Day at UCA Rochester @ A Martin-Bowtell

artistic responses to their experience of working with primary resources from the animation archive at UCA. The project aimed to raise the profile of our archive collections, going beyond 'open shelf' resources, and to enhance awareness of the wide scope and accessibility of collections within the library.

\section{The challenges of location}

UCA, although established as a university in 2008, is the result of various mergers of art schools that have existed since the 1870s. Due to this we currently operate over four sites. Our geographical split is two campuses in Surrey (Farnham, and Epsom) and two in Kent (Canterbury and Rochester) all of which house archives and special collections. There is no centralised archive repository, archives are held in closed access strong rooms within each library, from which materials are retrieved on request. Library collections mirror this distribution, with a library at each campus. The benefits of this situation allow our collections to be focussed on local subject specialist needs whilst allowing our users to request materials and access the full breadth of the collection from all four sites. As decried by Victor, Otto and Mutschler in their article published in 2013 in the journal Collaborative Librarianship:

The archives and special collections are an important part of university libraries. However, they are often an underutilized resource because they tend to be isolated from the rest of the library. This isolation hampers relationshipbuilding with fellow librarians, as well as missed opportunities to participate in information literacy initiatives that expose students to archive resources. ${ }^{2}$

The collaboration between archivist and librarian at UCA was borne out of a need to raise awareness of the full range of materials available, opening up the archives and contextualising their use alongside our open shelf collections, bringing the archives out of the strong room and directly into the students' hands.

The archives and special collections consist of individual artist archives, including the Bob Godfrey Archive, organizational art archives such as The Diagram Visual Information Limited Group, and our institutional archives.

Our aim as providers of library services and resources is to 'deliver outstanding resources and services which promote excellence in learning, teaching and research in the creative arts. ${ }^{3}$ As 
discussed, this cannot be achieved if the student body considers a vast section of these resources to be inaccessible. To ensure that the university archive resources were used to their best advantage it was agreed that the work of the archivist should be incorporated into the existing learning and teaching programmes used by librarians.

\section{The role of the librarian and archivist in teaching and learning}

The Learning and Teaching Librarian role at UCA, like at many other UK universities, has a focus on teaching and enhancing information literacy skills. Librarians support students working in a range of arts disciplines, at different levels from Further Education to $\mathrm{PhD}$. The majority of time is spent on the planning and delivery of information literacy and academic skills. This takes the form of a point of need delivery, in which our support for students is fully embedded into the curriculum, making our teaching and learning enhancement wholly relevant to their academic work and studio-based practice.

Librarians ensure continued, high quality and, most important across a geographically-challenged four-site university, consistent support by structuring the teaching we provide by planning and delivering our teaching to agreed outcomes, supporting the student journey, research and the production of academic and artistic work. We include in this principles of academic integrity, information literacy, study skills, as well as broader skills such as problemsolving, communication and team-work. Learning outcomes of all library and research sessions seek to empower students with these skills, tailored to the learning outcomes of the unit the session supports, an approach now adopted by the archivist. With the established teaching practice in place, the next challenge was to decide the most appropriate means of using archives in arts teaching and learning at UCA.

\section{Why use archive materials with arts students?}

An advocate of archive use and the skills this can develop, Gillian Spraggs emphasizes the benefits of engaging with archive material. In case studies of university history students using archives in their research, it was found that:

Students find this immensely exciting. Sifting through archive documents, struggling to understand and contextualize them, they gain a much deeper appreciation of the problems inherent in using documentary sources, and the resourcefulness and creative thinking needed to interpret them. They enjoy the detective work of looking for clues and making connections. They are inspired by finding that they can make their own discoveries... ${ }^{4}$

Students are not only working with archive materials to discover new resources and to acquire knowledge of their subject but they are, '...learning to extract information from a large amount of disparate material, locate and access different types of resources, appreciate characteristics of different types of documents, and assess their properties as evidence. ${ }^{5}$

These are information literacy skills that we want students to use with our library resources in their research but also to carry with them beyond university and into their careers and lives. Many arts professions require the practitioner to undertake research, whether it is for branding or marketing of a product or work. History students may seem natural candidates for archival research but our arts students also need to acquire these skills.

Some of the challenges we can face in arts archives provision and access are that the visual rather than text based often has more of an appeal with our students. Digitization is an excellent way to stimulate initial interest, but due to copyright issues (often with multiple copyright holders in art collections) it is not always possible to put all images online to attract students in the first instance. Due to the necessary security and access procedures within an archive setting, it can seem intimidating to someone who is used to a more open shelf setting. Without being able to browse the collection students may not feel tempted to explore in the same way they would peruse a shelf in the library. It is, therefore, necessary to bring archives to the students.

\section{The Bob Godfrey Studio Archive}

The pairing of the CAA department with the Bob Godfrey Archive was a natural one. Students on the course use the latest technology to explore all aspects of animation. Much of the material in the Bob Godfrey archive includes outmoded resources, illustrating methods and techniques which are not commonly used in contemporary animation practice, in particular acetate cels and dope sheets. A dope sheet is an animator's chart which details production instructions, e.g. camera timings and directions. 
This allowed the students to explore and consider the historical aspects of the animation process and sparked discussion and further understanding of who Bob Godfrey was, as well as how he made his animations.

The Bob Godfrey Studio Archive demonstrates the remarkable career of an internationally celebrated animator, and founder of the Animation programme at UCA in 1973. The physical materials in the collection reveal the artistic spirit and essence of a witty, rebellious and ground-breaking animator. With a distinctively British style, Bob Godfrey produced a wide variety of animated films, from the Oscar-winning Great to BAFTA winners Henry 9 to 5 and Henry's Cat, along with cult shorts and children's TV series such as Roobarb and Custard.

The studio also made award-winning independent short films including Do it yourself cartoon kit and Kama Sutra rides again. The collection features a vast number of original cels, drawings, storyboards and correspondence from Godfrey's films that illuminate the relationship between the arts-based materials and the creative processes of pre-digital animation.

\section{Practicalities of using the archive materials in the studio}

We of course designed the Animation Archive Day to be a 'hands on' session to actively engage the students, but issues concerning the use of archive materials in the studio had to be considered. The impact on preservation and the security of the collection are major issues to navigate, when using archives outside of the library setting. The studio can be of particular concern, due to the presence of art materials. We mitigated this by ensuring that the surface area was clean, groups were kept to a manageable size, and at least two members of staff were on hand to supervise the group. We also requested that students only use pencils, and had no food or drink in the studio. Staff demonstrated how to correctly handle the documents, a key issue for the kinds of materials found in an animation archive. Acetate cels can be particularly difficult, as acetate often adheres to other materials within the collection, including paper. This has the potential to cause damage such as flaking paint and tearing to the cels. Staff were on hand to help handle the collection and badly damaged articles were not selected for student use.

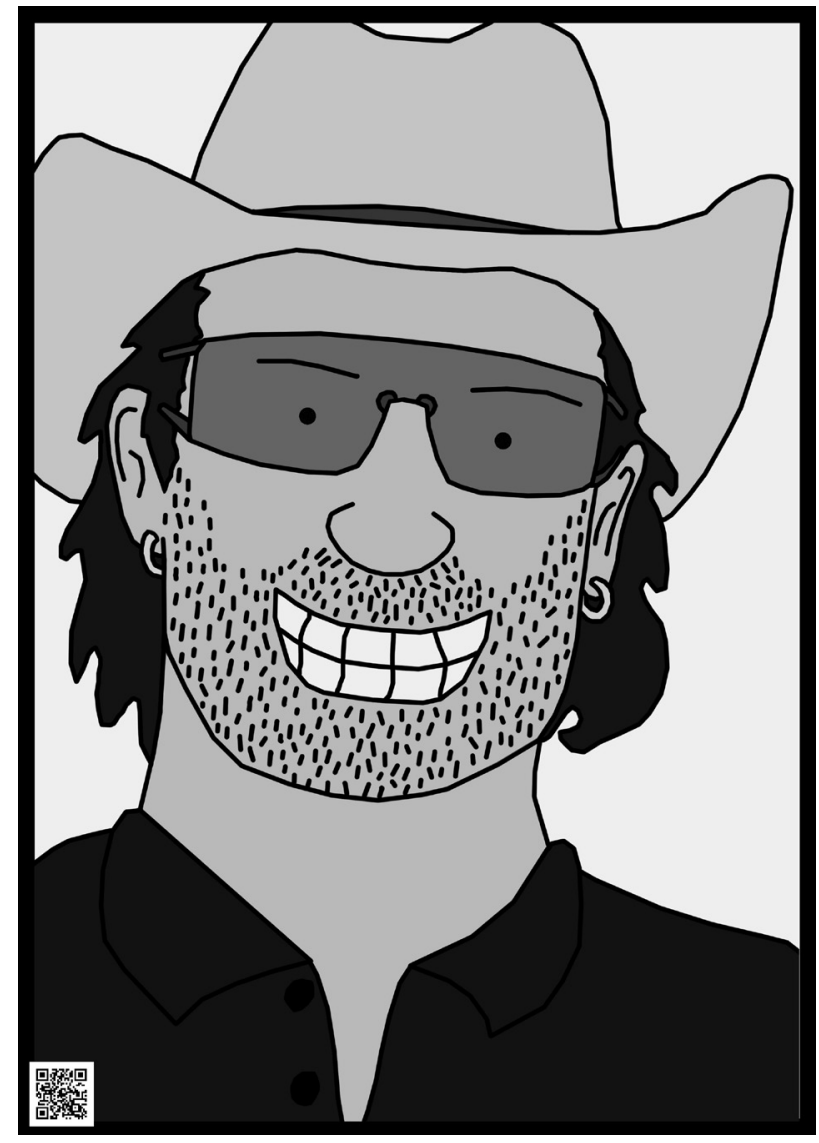

Fig. 2. An image of Bono in the style of Bob Godfrey's animation created in response to Animation Archive Day (C) Jake Bryant

\section{Animation Archive Day}

The day itself saw first year students from the Computer Animation Arts course attend a teaching session with the librarian, archivist and academic staff in the departmental studio. The learning outcomes of the session were as follows:

Students will understand the differences between

- Primary and secondary resources

- Archival and library resources, formats, access, uses

Students will know how to

- handle archive materials

- access our collections (both archive and library)

The session was designed to facilitate discussion and discovery. The course leader's input ensured that the session would be pitched at the correct level and relate to first year, practical, studio work. We wanted to guarantee that the day was fully embedded into the course, so through careful timetabling, at the advice of the course leader, an appropriate point in the course was identified and the day arranged. The Animation Archive Day would facilitate the change of focus from the creation of spaces and 
environments for animation to the creation of characters and story telling, bridging the gap in the transition time between the units of study. The need for this kind of collaborative planning, delivery and timing of such sessions is vital if students are to be discouraged from thinking of library and archive sessions as optional and irrelevant to their studies.

Students were asked to view three episodes of Godfrey's animation Henry's Cat prior to the session. URL links were added to the virtual learning environment (VLE) to enable this. Pre-viewing was necessary as the students were too young to remember the original television series, which aired in the 1980s. During the session a variety of materials relating to those three episodes were laid out for the students to access freely. They included:

- cel animation sheets used for the filming of the cartoon series

- original illustrations from the series

- timing and dope sheets

- books from Bob Godfrey's personal collection with his own annotations and sketches

During the session the librarian and archivist led discussion on the differences between primary and secondary resources. Students were able to explore archive materials including the original sketches for the animation Henry's Cat. A lecturer was present and was able to discuss the cel animation process with the students using the sheets, to illustrate this and to explain how the unfamiliar techniques were used to produce the resulting animation.

The librarian and archivist facilitated discussion regarding the objects and encouraged students to consider the archive materials in light of:

- possible uses in their academic research and studio practice

- what types of resources these were primary/ secondary

- how conventional library resources 'fitted' with archive materials

- how further research could contextualize these resources and allow for a more informed analysis Students were fascinated and fully engaged with the materials and discussions. Frequently asked questions included 'Am I allowed to touch these?'; 'Are they the original?'; 'Where are these kept?'; 'Can I see them again?'; and 'How do I see more?'

\section{Responding artistically to archive use}

Being an arts university and inspired by work from other such institutions, the students were encouraged to respond artistically to the session. Students and practitioners engaging with, and being

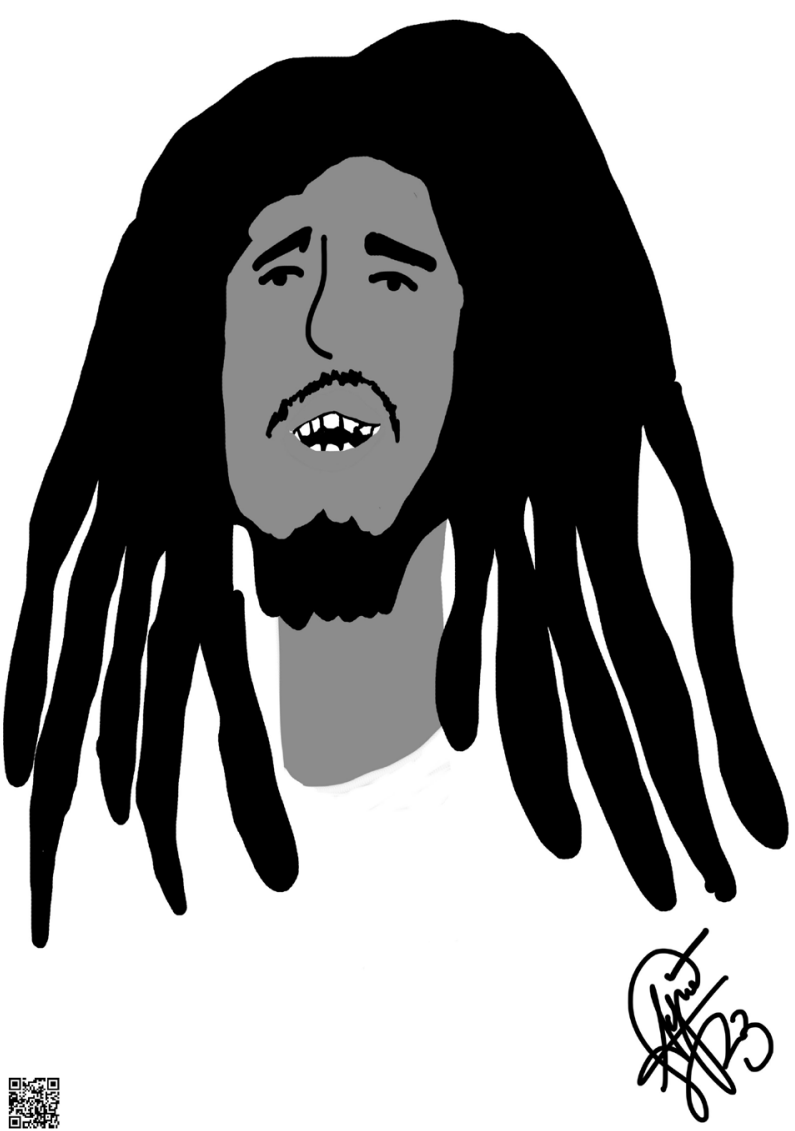

Fig. 3. An image of Bob Marley in the style of Bob Godfrey's animation created in response to Animation Archive Day @Ayunie Adiana

inspired by, archival material is a current area of study in the archive world where it is encouraged and promoted. One of the most vocal of its advocates, The National Archives, champions an initiative, Archiving the Arts. They describe this as '....an initiative to ensure that the records of the arts in the UK are well cared for and accessible, and that their value is recognized, by the people who create and look after them and by the wider public' ${ }^{6}$

Increasingly art historians and archivists are exploring how the history of the arts, represented through archive documents and materials, inspires new artists. This is also reinforced by practitioners such as Animate Projects which describes itself as, '....an internationally renowned strategic agency working out of Derby and London that supports and champions creative animation practice'. In their overview of the animation industry and its practitioners, the resulting Accelerate animate report $2013^{8}$ states that in order to develop skills animators need reflection, inspiration and guidance from the work of contemporaries and predecessors. Here the role of the animation archive in animation education is evidenced and advocated by the industry itself.

The legacy of Animation Archive Day was to initiate an artistic response to the experience. 
Students were given the task of creating a digital image of a character or celebrity realized in the style of Bob Godfrey's work. It was to take place in the time between units and inspire the students to begin to think about the characterization work they would begin in the next unit of study in their course. Work was submitted to the librarian and the project team then met with the cultural programme curator to discuss how the work could be exhibited. Funds were successfully secured and the librarian worked with departmental technicians to produce high quality prints of the images for the exhibition. Each image included a QR code linking directly to the artists' blog. Blogs form an integral part of students work on the BA Hons Computer Animation Arts course, to showcase all stages of animation work and its processes, as well as finished pieces. More importantly, from an information and academic literacy point of view, they enable students to critically reflect on their work, research and development as artists. Each image in the exhibition by linking to a blog embodied the project's role in the department, individual student development, research, reflection and artistic response to archive use.

The exhibition took place at the Rochester campus where the Animation Archive Day had been held four months earlier. After the exhibition the images produced by the students will be added to and catalogued within the university archives and special collections for future learning and teaching. As well as incorporating the physical prints into the collection, we will add the original images and photographs of the exhibition to UCA's digital image repository. This material will be used in future student inductions and workshops and will be available for students to access as archive materials in their own right.

In conclusion the Animation Archive Day encouraged students to explore primary and secondary resources taken from both the archive and library collections. It enabled students to research, reflect, interpret, and respond, creating new archive material from their learning experience. It has raised student and staff awareness of the expandable and widely accessible archive and complex teaching and learning resource available across a geographicallydivided university, and it aligned the teaching role of the archivist with that of the librarian. The project continues to draw together a broad range of specialist staff to facilitate access and use of archive resources in a library context at the University for the Creative Arts.

\section{References}

1. The Society of American Archivists, Glossary of Archival and Records Terminology, accessed 7 May 2014, www2.archivists.org/glossary/terms/a/ archives

2. Paul Victor Jr., Justin Otto and Charles Mutschler, 'Assessment of library instruction on undergraduate student success in a documentsbased research course: the benefits of librarian, archivist, and faculty collaboration', Collaborative librarianship 5, no.3 (2013):154-176.

3. University for the Creative Arts Library and learning services strategy 2012-2015, accessed 2 May 2014, http://btc02.files.wordpress. com/2012/06/library-learning-services-strategy2012-15-final.pdf

4. Gillian Spraggs, 'Using Archives in Higher Education History Teaching'. The National Archives. Accessed 2 May 2014, www.archives. org.uk/images/documents/AfELG/AfELG_ Conference_13_June_2011/Using_Archives_in_ Higher_Education_History_Teaching.pdf (a)

5. ibid.

6. The National Archives, Archiving the Arts, accessed 2 May 2014, www.nationalarchives.gov. $\mathrm{uk} /$ archives-sector/archiving-the-arts.htm

7. Animation Alliance, Accelerate animation report 2013: animation art and craft: responding to the creative animation sector's practice and professional development needs. Accessed 2 May 2014, accelerateanimation.com/category/acceleratereport/

Adele Martin-Bowtell
Learning and Teaching Librarian
University for the Creative Arts
Fort Pitt
Rochester
Kent
ME1 1DZ
UK
Email:amartin-bowtell@ucreative.ac.uk

Rebekah Taylor

Archivist and Special Collections Officer

University for the Creative Arts

Falkner Road

Farnbam

Surrey

GU9 7DS

$U K$

Email:rtaylor8@ucreative.ac.uk 